\title{
Selective decline in memory function among healthy elderly
}

\author{
Scott A. Small, MD; Yaakov Stern, PhD; Ming Tang, PhD; and Richard Mayeux, MD, MSC
}

\begin{abstract}
Article abstract-Objective: To use longitudinally acquired data to establish whether aging is associated with memory decline. Background: Memory loss is one of the most frequent complaints among the elderly. Nevertheless, age-related memory decline remains controversial in large part because it has been established with cross-sectional studies. Methods: A total of 212 community-based healthy people were followed prospectively and evaluated annually with a neuropsychological battery testing memory and other cognitive domains. To control for the learning effect-the improvement in test performance associated with repeated exposure-longitudinal performance was compared between two age groups. $R e$ sults: The older age group displayed a relative decline in memory performance with time. In contrast to memory, a relative age-related decline was not observed in tests of language, visuospatial ability, and abstract reasoning. Furthermore, within the memory domain, age-related decline was restricted to a specific aspect of memory, manifesting only in a measure sensitive to the acquisition and early retrieval of new information, and not in a measure of memory retention. This profile of age-related cognitive decline anatomically localizes to the hippocampal formation. Conclusion: This study establishes age-related memory decline using longitudinal data, and shows that this decline does not occur diffusely across multiple cognitive domains. Both early $\mathrm{AD}$ as well as non-AD processes likely contribute to age-related memory decline, and continued follow-up may reveal distinguishing features between these two.
\end{abstract}

NEUROLOGY 1999;52:1392-1396

Formal investigations of memory and aging began over 40 years ago, ${ }^{1}$ and since then numerous studies have attempted to document the existence of agerelated memory decline, characterize its clinical presentation, and propose possible etiologies (see Craik et al. $^{2}$ for review). Nevertheless, and despite memory decline being one of the most common neurologic complaints among the elderly, age-related memory decline remains controversial. ${ }^{3}$ One source of controversy concerns the choice of reference in categorizing an elderly person as having memory decline. Most studies have used cross-sectional comparisons. For example, a work group of the National Institute for Mental Health have proposed criteria for "age-associated memory impairment," "where the reference used was the mean performance of younger people on memory tests. In contrast, Blackford and La Rue ${ }^{5}$ proposed norms established with elderly people to define "latelife forgetfulness." More recently, Smith et al. ${ }^{6}$ have developed more extensive normative data for elderly people, and use these norms as a reference for "mild cognitive impairment."

There remain lingering concerns about crosssectional findings because of the sensitivity of memory tests to demographic differences. ${ }^{7}$ Although an attempt can be made to control for some differences among cohorts of varying ages, the effect of generational differences-such as unequal levels ed- ucation and exposure to different environmental stimuli-cannot be accounted for. Furthermore, an elderly person whose memory performance is less than a group norm would be categorized as having memory decline, even if longitudinal follow-up showed that this person had stable memory over time. ${ }^{8}$ Thus, longitudinal analysis is a more direct method for documenting memory decline. ${ }^{8,9}$

Administering a memory test multiple times, as would be required for longitudinal analysis, results in improving memory performance. ${ }^{9,10}$ This occurs even if test items are changed, and therefore this effect is likely caused by the implicit learning of test-taking skills. This learning effect can obscure an underlying decline in explicit, or declarative, memory ability. In fact, only a few studies ${ }^{11,12}$ have succeeded in documenting memory decline longitudinally, requiring infrequent follow-up over long periods.

In this study, we attempt to demonstrate agerelated memory decline by comparing longitudinal memory performance between two age groups, using prospectively acquired data. Based on the assumption that the learning effect does not change across different age groups, ${ }^{9,10}$ the underlying hypothesis is that differences that emerge in longitudinal memory performance result from differences in declarative memory.

Methods. Subjects. Subjects were drawn from the Washington Heights Inwood Aging Project. This is a

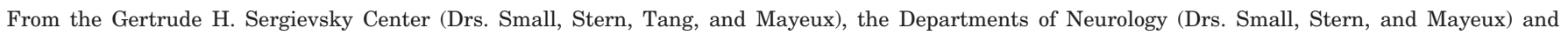

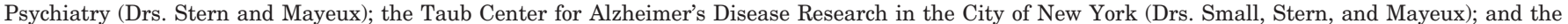

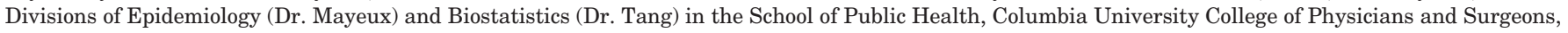
New York, NY.

Supported by National Institute of Aging grants AG07232, AG08702, and AG01963.

Received August 5, 1998. Accepted in final form January 1, 1999.

Address correspondence and reprint requests to Dr. Scott A. Small, Gertrude H. Sergievsky Center, 630 West 168 Street, New York, NY 10032. 
community-based random sample of elderly people who reside in a single community in northern Manhattan. Enrolled subjects are followed prospectively and receive annual medical, neurologic, and neuropsychological evaluations. Data from these evaluations are presented at a consensus conference made up of neurologists and neuropsychologists and are used determine those subjects who fulfill Diagnostic and Statistical Manual of Mental Disorders, 4th ed. (DSM-IV) ${ }^{13}$ criteria for dementia, and those who have cognitive impairment but no dementia (assigned to subjects whose cognitive impairment is not sufficiently extensive, or who do not have associated decline in their functional ability ${ }^{14}$ ).

For this study, people diagnosed with dementia or cognitive impairment without dementia, at any time point, were excluded. Likewise, subjects with a history of stroke, PD, or depression were excluded. From the remaining 539 people, only those with four completed evaluations were considered for this study. A total of 212 subjects, ranging from 60 to 93 years of age, fulfilled these exclusionary and inclusionary criteria.

Neuropsychological testing. All subjects underwent neuropsychological testing of multiple domains. Orientation was evaluated using items from the modified MiniMental State Examination. ${ }^{15}$ Language was evaluated using the Boston Naming Test, ${ }^{16}$ the Controlled Word Association test, ${ }^{17}$ category naming, the Complex Ideational Material Subtest of the Boston Diagnostic Aphasia Evaluation (BDAE), ${ }^{18}$ and the BDAE repetition of phrases. ${ }^{18} \mathrm{Ab}$ stract reasoning was evaluated using Wechsler Adult Intelligence Scale-Revised similarities, ${ }^{19}$ and the nonverbal similarities subtest of the Mattis Dementia Rating Scale. ${ }^{15}$ Visuospatial ability was evaluated using the Rosen Drawing Test ${ }^{20}$ and a matching version of the Benton Visual Retention Test. ${ }^{21}$ Memory was evaluated using a multiple-choice version of the Benton Visual Retention Test $^{21}$ and the Selective Reminding Test (SRT). ${ }^{22}$

The $\mathrm{SRT}^{22}$ was developed to assess the acquisition, retention, and retrieval of a list of words. The initial stimulus presentation consists of 12 words read aloud that the subject is asked to recall. Subsequent presentations consist of only those words that the subject omitted from the previous trial, and the subject is asked to recall the entire list. The procedure is repeated for six consecutive trials. Delayed recall is assessed after a 15-minute delay. Three performance scores, based on performance in the first six trials, were initially developed to distinguish between acquisition and retrieval. These scores have been found to be highly intercorrelated ${ }^{23}$ and likely measure a similar process that relates to the acquisition and early retrieval of new words. For this study, we used the total recall score. The score is the total items the subject recalled across all six trials. Memory retention was assessed by determining the ratio of words recalled after the 15-minute delay to the number of words recalled on the sixth trial.

Statistical analysis. Longitudinal data from these tests were analyzed using Generalized Estimated Equations (GEE). ${ }^{24} \mathrm{GEE}$ is based on regression models that do not require outcome measures to be independent of each other (in this case, the repeated neuropsychological test scores), and it does not require that these measures have a gaussian distribution. GEE uses the correlations among outcome measures to improve statistical power. For this study, GEE analyses were performed to assess for differences in longitudinal performance among different age groups, and the main variables were age group, time, and age group $\times$ time. Preliminary analyses showed that results did not differ whether time was included as a continuous or a categorical variable. All final analyses included time as a continuous variable. An "exchangeable" working correlation structure was used. This structure assumes that changes between different interval years are equivalent.

The following were evaluated for inclusion as covariates: ethnicity, gender, education (dichotomized by median years of education), and the interactions of ethnicity, gender, and education with time. Because of the regression to the mean effect associated with repeated testing, "baseline score" (dichotomized by median performance score at baseline) and the interaction of baseline score with time were also evaluated as covariates. For each GEE analysis, we included all six of the covariates into the initial model, and then trimmed back the model, retaining only those covariates that significantly contributed.

Regression coefficients from these GEE analyses represent associations between a neuropsychological score and variables included in the model. A significant age group effect indicates a difference between two groups at the baseline evaluation, with a positive regression coefficient indicating that the younger group had greater scores than the older group. A significant time effect indicates a change of test scores over time, with a positive regression coefficient indicating improving scores for the younger group. If the age group $\times$ time effect is smaller than the time effect, this indicates that both age groups had improving scores over time. Because the aim of this study was to evaluate longitudinal performance, the most important variable under consideration is the age group $\times$ time interaction effect. A significant age group $\times$ time regression coefficient indicates that the change in scores over time is different for the two age groups. A negative regression coefficient indicates that the older group has a relative decline compared with the younger group.

Driven by the primary hypothesis of this study, the first GEE analysis was performed for the total recall scores of the SRT. Subsequent analyses were then performed using measures of other cognitive domains.

Results. Subjects were initially stratified into three age groups: younger than 70, 70 to 79 , and older than 80 years. A preliminary GEE analysis showed that there was no age group $\times$ time interaction between 70 - and 80-year-olds ( $\beta=0.11 ; p=0.74)$, and the age groups were therefore collapsed from three to two-subjects younger than 70 years of age, and subjects 70 years of age and older. Table 1 presents the demographics of the two age groups, and aside from mean age, the two groups did not significantly differ from each other across these variables.

The first set of GEE analyses was performed to assess longitudinal memory performance between the two age groups using total recall and retention scores of the SRT as the dependent variables. For the total recall scores, there was a significant age-group effect $(\beta=-2.0, p=0.016)$ and a significant time effect $(\beta=0.71 ; p=0.001)$. Furthermore, there was a significant negative age group $\times$ time interaction $(\beta=-0.44 ; p=0.039)$. This indicates that the older group had a relative decline in total recall scores 
Table 1 Characteristics of the two age groups used for analysis

\begin{tabular}{lll}
\hline & Younger group & Older group \\
\hline No. of subjects & 91 & 121 \\
Mean age, y (range) & $66.1(60-69)$ & $75.7(70-93)$ \\
Sex, \% female & 62.6 & 72.7 \\
Ethnicity, \% nonminority white & 54.2 & 55.1 \\
Mean years of education & 11.0 & 10.7 \\
\hline
\end{tabular}

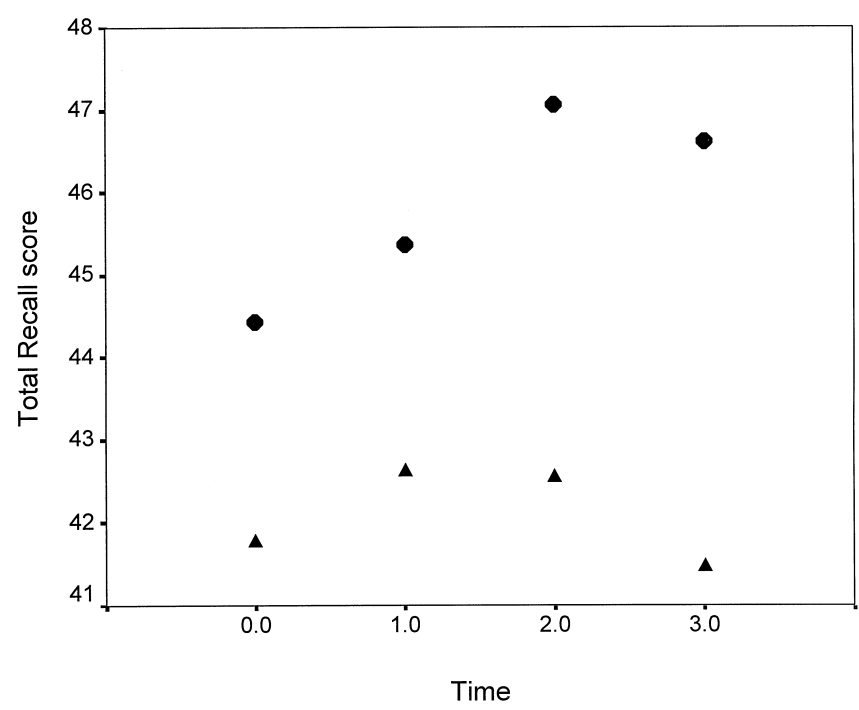

Figure 1. Change in memory performance over time for the two age groups. Memory was evaluated repeatedly using the Selective Reminding Test. The circles represent the younger age group (60 to 69 years of age); the triangles represent the older age group (70 to 93 years of age). The older age group showed a relative decline in memory performance. compared with the younger group. These results are presented graphically in figure 1 . For memory retention, a significant time effect $(\beta=0.02, p=0.003)$ but no significant age group $\times$ time interaction was found, indicating that both age groups improved in a parallel fashion.

A second set of GEE analyses was performed to assess for relative decline in other cognitive domains. Scores of other neuropsychological tests were used as the dependent measures, and the same independent measures were used. The results are summarized in table 2. Although most groups had a positive time effect, showing a learning effect, no score was found to have a significant age group $\times$ time effect. These results are exemplified with the Boston Naming Test, as shown in figure 2.

Discussion. Following a single cohort over time is a powerful design for demonstrating a suspected agerelated change in cognition. The advantages of longitudinal analysis, however, are obscured if the act of multiple testing influences the dependent measure of interest. For tests of declarative memory such as the SRT used in this study, the observed longitudinal performance is a composite of two processeschanges in ability to acquire and retrieve a set of words at a given time point, and changes in testtaking skills acquired through previous testing. Consistent with other studies suggesting the preservation of the learning effect with aging, ${ }^{9,10}$ we found that for most tests both age groups had similar improvement in performance with repeated testing (see figure 2). This suggests that all subjects retained the ability to acquire test-taking skills, and that the relative decline found in longitudinal memory performance observed in the older age group cannot be explained by an age-related decline in procedural learning. Comparing longitudinal data cross-sectionally effectively con-

Table 2 Summary of results comparing longitudinal performance between both age groups across multiple cognitive domains*

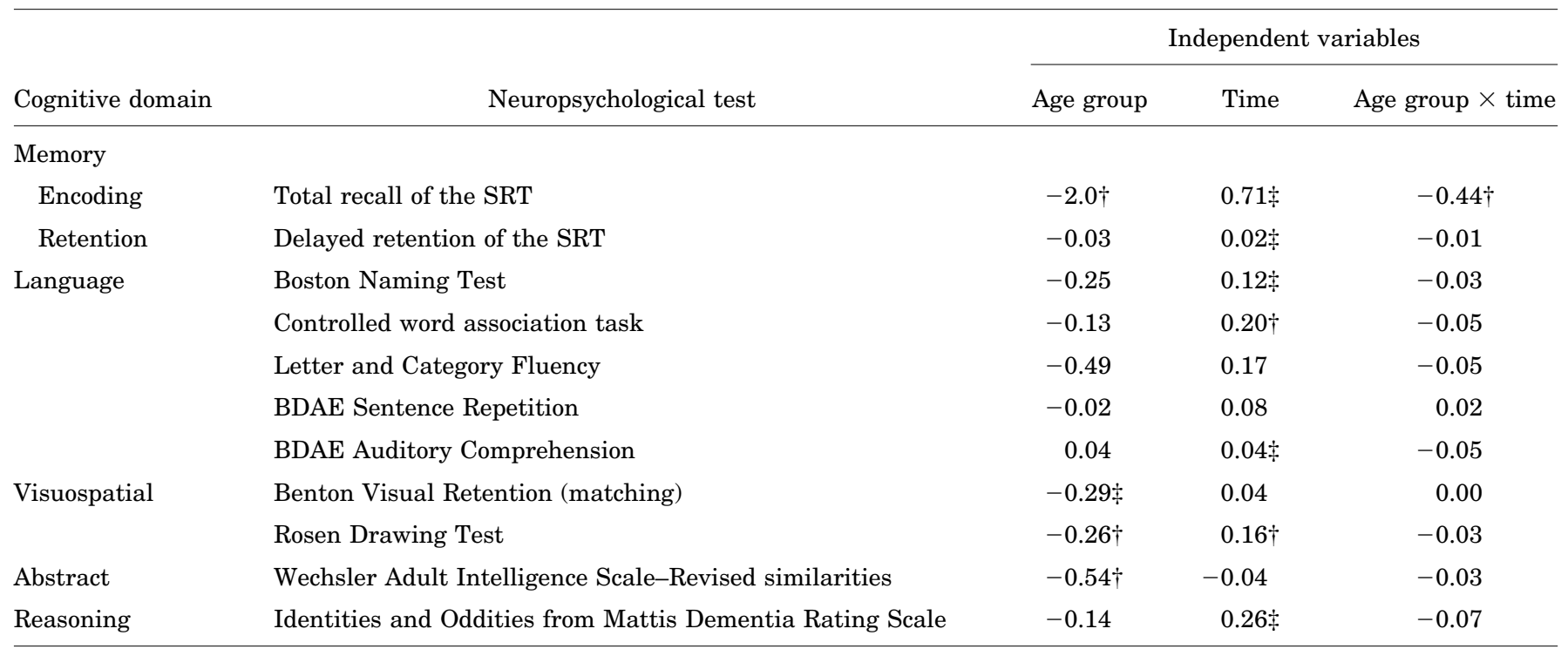

* Each analysis was adjusted for contributing covariates. Values are given as regression coefficients.

$\dagger p \leq 0.05$.

$\ddagger p \leq 0.01$.

BDAE $=$ Boston Diagnostic Aphasia Evaluation; SRT $=$ Selective Reminding Test. 


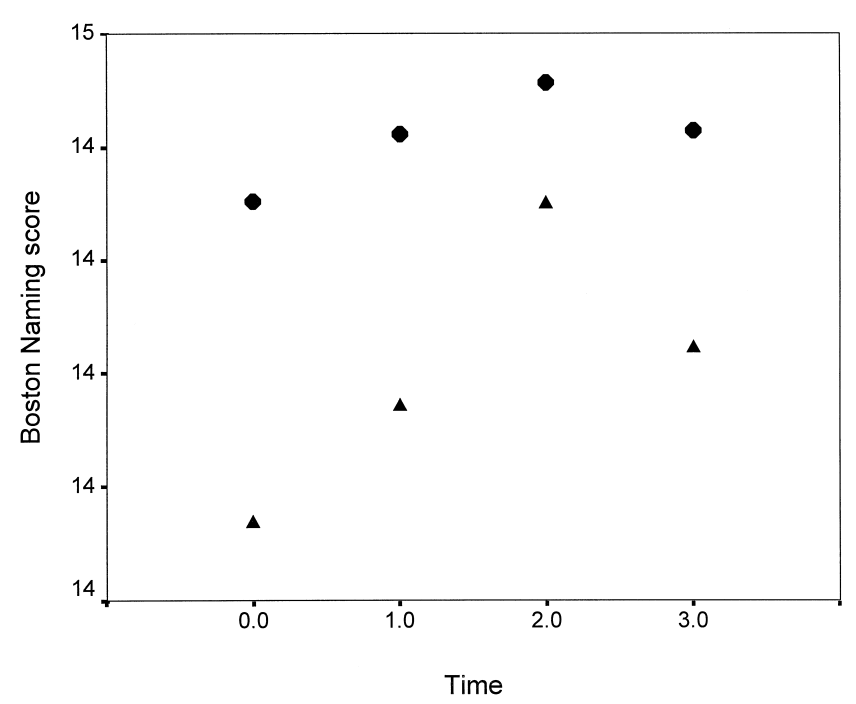

Figure 2. Change in performance on the Boston Naming Test over time for the two age groups. The circles represent the younger age group (60 to 69 years of age); the triangles represent the older age group (70 to 93 years of age). Both age groups showed a similar improvement in performance with repeated exposure.

trolled for the learning effect, and the described difference results from an age-related memory decline. This finding should address lingering doubts regarding the existence of age-related memory decline.

A second finding of this study is that across cognitive domains, age-related decline is specific to memory function. In contrast to memory, a relative age-related decline was not observed in five tests of language, two tests of visuospatial ability, and two tests of abstract reasoning. Furthermore, within the memory domain, we found that age-related decline was restricted to a specific aspect of memory. Thus, age-related memory decline manifested only in a measure that is most sensitive to the acquisition and early retrieval of new information, and not in a measure of memory retention. A limitation of this study was that we did not administer a test of working memory, which has been shown to also undergo agerelated decline. ${ }^{25}$

These findings demonstrate that decline in higher-order functions are not diffuse, but selectively involve memory ability. The ability to acquire new information, and to retrieve this information shortly postacquisition, requires an intact hippocampal formation. ${ }^{26}$ Deficits in the SRT have been described in patients with selective hippocampal lesions, ${ }^{27}$ and it has been postulated that age-related memory decline localizes to this structure. ${ }^{28}$ There is an extensive body of literature documenting changes in the hippocampal formation that occur in an age-dependent fashion, ${ }^{28,29}$ and these are invoked to explain memory decline in aging animals.

Is age-related memory decline a normal occurrence-does it represent physiologic senescence-or does it represent a pathologic state? Because of a bimodal distribution of memory scores in aging ani- mals and humans, ${ }^{30}$ where many aged individuals perform as well as younger control subjects, age-related memory decline is thought not to be an inevitable consequence of aging. What, therefore, are possible underlying etiologies? The first brain structure to be targeted by $\mathrm{AD}$ is the hippocampal formation, ${ }^{31}$ and correspondingly, prospective studies have found that memory deficits are the first signs of $\mathrm{AD}{ }^{32,33}$ It is likely, therefore, that early $\mathrm{AD}$ is one contributing etiology of age-related memory decline. Non-AD processes should likewise be considered as potential contributors to age-related memory decline. There are a number of physiologic processes that change in humans in an age-dependent manner, ${ }^{34,35}$ some of which have been found to target the hippocampal formation and result in memory impairment. ${ }^{36-38}$ Although it possible that some of these processes may interact with $\mathrm{AD}$, recent postmortem studies have found age-dependent loss in specific hippocampal subregions among brains that were free from $\mathrm{AD}$ pathology. ${ }^{39,40}$

This study establishes the existence of age-related memory decline using longitudinal data and shows that this decline does not occur diffusely across multiple cognitive domains. Furthermore, age-related memory decline is differentially expressed in measures that are hippocampal dependent. Both early $\mathrm{AD}$ and non- $\mathrm{AD}$ processes likely contribute to this memory decline, although it is difficult to dissociate these potential causes. By continuing to follow these subjects prospectively, we hope to determine the incidence of $\mathrm{AD}$, and retrospectively determine how to distinguish those who do and do not progress to dementia.

\section{References}

1. Kral VA. Neuro-psychiatric observation in an old peoples' home. Studies of memory dysfunction in senescence. J Gerontol 1958;13:169-176.

2. Craik FIM, Anderson ND, Kerr SA, Li KZH. Memory changes in normal ageing. In: Baddely $\mathrm{AD}$, Wilson BA, Watts FN, eds. Handbook of memory disorders. New York: John Wiley \& Sons, 1995:211-242.

3. Larrabee GJ, McEntee WJ. Age-associated memory impairment: sorting out the controversies. Neurology 1995;45:741747.

4. Crook T, Bartus RT, Ferris SH, Whitehouse P, Cohen BE, Gershon S. Age-associated memory impairment: proposed diagnostic criteria and measures of clinical change. Report of a National Institute of Mental Health Work Group. Developmental Neuropsychology 1986;2:261-267.

5. Blackford RC, La Rue A. Criteria for diagnosing ageassociated memory impairment: proposed improvement from the field. Developmental Neuropsychology 1989;5:295-306.

6. Smith GE, Petersen RC, Parisi JE, et al. Definition, course, and outcome of mild cognitive impairment. Aging Neuropsychol Cogn 1996;3:141-147.

7. Heaton RK, Grant I, Matthews CG. Differences in neuropsychological test performance associated with age, education, and sex. In: Grant I, Adams KA, eds. Neuropsychological assessment of neuropsychiatric disorders. New York: Oxford University Press, 1986:100-120.

8. Smith G, Ivnik RJ, Petersen RC, Malec JF, Kokmen E, Tangalos E. Age-associated memory impairment diagnoses: problems of reliability and concerns for terminology. Psychol Aging 1991;6:551-558.

9. Flicker C, Ferris SH, Reisberg B. A longitudinal study of cog- 
nitive function in elderly persons with subjective memory complaints. J Am Geriatr Soc 1993;41:1029-1032.

10. Zeliniski EM, Gilweski MJ, Shaie KW. Individual differences in cross-sectional and 3-year longitudinal performance across the adult life span. Psychol Aging 1993;8:176-186.

11. Colsher PL, Wallace RB. Longitudinal application of cognitive function measures in a defined population of communitydwelling elders. Ann Epidemiol 1991;1:215-230.

12. Zelinski EM, Burnight KP. Sixteen-year longitudinal and time lag changes in memory and cognition in older adults. Psychol Aging 1997;12:503-513.

13. American Psychiatric Association. Diagnostic and statistical manual of mental disorders. 4th ed. Washington, DC, American Psychiatric Association, 1994.

14. Stern Y, Andrews H, Pittman J, et al. Diagnosis of dementia in a heterogeneous population: development of a neuropsychological paradigm-based diagnosis of dementia and quantified correction for the effects of education. Arch Neurol 1992;49: 453-460.

15. Mattis S. Mental status examination for organic mental syndrome in the elderly patient. In: Bellak L, Karasu TB, eds. Geriatric psychiatry. New York: Grune and Statton, 1976:77-121.

16. Kaplan E, Goodglass H, Weintraub S. Boston naming test. Philadelphia: Lea \& Febiger, 1983.

17. Benton AL, Hamsher K. Multilingual Aphasia Examination. Iowa City: University of Iowa, 1976; revised, 1978.

18. Goodglass H, Kaplan D. The assessment of aphasia and related disorders. 2nd ed. Philadelphia: Lea \& Febiger, 1983.

19. Wechsler D. WAIS-R manual. New York: The Psychological Corporation, 1981.

20. Rosen W. The Rosen drawing test. New York: Veterans Administration Medical Center, 1981.

21. Benton AL. The visual retention test. New York: The Psychological Corporation, 1955.

22. Buschke H, Fuld PA. Evaluating storage, retention, and retrieval in disordered memory and learning. Neurology 1974; 24:1019-1025.

23. Loring DW, Papanicolau AW. Memory assessment in neuropsychology: theoretical consideration and practical utility. J Clin Exp Neuropsychol 1987;39:451-454.

24. Liang KY, Zeger SL. Longitudinal data analysis using generalized linear models. Biometrika 1986;73:13-22.

25. Salthouse TA. Mediation of adult age differences in cognition by reduction in working memory and speed of processing. Psychological Science 1991;2:179-183.

26. Zola-Morgan S, Squire LR. Neuroanatomy of memory. Annu Rev Neurosci 1993;16:547-563.
27. Sass KJ, Spencer DD, Kim JH, Westerveld M, Novelly RA, Lencz T. Verbal memory impairment correlates with hippocampal pyramidal cell density. Neurology 1990:40:16941697.

28. Geinisman Y, Detoledo-Morrell L, Morrell F, Heller RE. Hippocampal markers of age-related memory dysfunction: behavioral electrophysiological and morphological perspectives. Prog Neurobiol 1995;45:223-252.

29. Barnes CA. Normal aging: regionally specific changes in hippocampal synaptic transmission. Trends Neurosci 1994;17:1318.

30. Rapp PR, Amaral DG. Individual differences in the cognitive and neurobiological consequences of normal aging. Trends Neurosci 1992;15:340-345.

31. Braak H, Braak E. Evolution of the neuropathology of Alzheimer's disease. Acta Neurol Scand 1996;165:3-12.

32. Masur DM, Sliwinski M, Lipton RB, Blau AD, Crystal HA. Neuropsychological prediction of dementia and the absence of dementia in healthy elderly persons. Neurology 1994;44:14271432 .

33. Jacobs DM, Sano M, Dooneief G, Marder K, Bell KL, Stern Y. Neuropsychological detection and characterization of preclinical Alzheimer's disease. Neurology 1995;45:957-962.

34. Belanger A, Candas B, Dupont A, et al. Changes in serum concentrations of conjugated and unconjugated steroids in 40 to 80 year old men. J Clin Endocrinol Metab 1994;79:10861090 .

35. Meyer JS, Terayama Y, Takashima S. Cerebral circulation in the elderly. Cerebrovascular \& Brain Metabolism Reviews 1993;5:122-146.

36. de Leon MJ, McRae T, Rusinek H, et al. Cortisol reduces hippocampal glucose metabolism in normal elderly but not in Alzheimer's disease. J Clin Endocrinol Metab 1997;82:32513259 .

37. de la Torre JC, Park G, Fortin T, et al. Loss of hippocampal neurons after chronic brain hypoperfusion in aged rats. Neurobiol Aging 1990;11:328-329.

38. Jacobs DM, Tang MX, Stern Y, et al. Cognitive function in nondemented older women who took estrogen after menopause. Neurology 1998;50:368-373.

39. West MJ. Regionally specific loss of neurons in the aging human hippocampus. Neurobiol Aging 1993;14:287-293.

40. Simic G, Kostovic I, Winblad B, Bogdanovic N. Volume and number of neurons of the human hippocampal formation in normal aging and Alzheimer's disease. J Comp Neurol 1997; 379:482-494. 


\title{
Neurology
}

\author{
Selective decline in memory function among healthy elderly \\ Scott A. Small, Yaakov Stern, Ming Tang, et al. \\ Neurology 1999;52;1392 \\ DOI 10.1212/WNL.52.7.1392
}

\section{This information is current as of April 1, 1999}

\section{Updated Information \& Services}

\section{References}

Citations

Permissions \& Licensing

Reprints

\begin{abstract}
including high resolution figures, can be found at: http://www.neurology.org/content/52/7/1392.full.html
\end{abstract}

This article cites 26 articles, 7 of which you can access for free at: http://www.neurology.org/content/52/7/1392.full.html\#\#ref-list-1

This article has been cited by 22 HighWire-hosted articles: http://www.neurology.org/content/52/7/1392.full.html\#\#otherarticles

Information about reproducing this article in parts (figures,tables) or in its entirety can be found online at:

http://www.neurology.org/misc/about.xhtml\#permissions

Information about ordering reprints can be found online: http://www.neurology.org/misc/addir.xhtml\#reprintsus

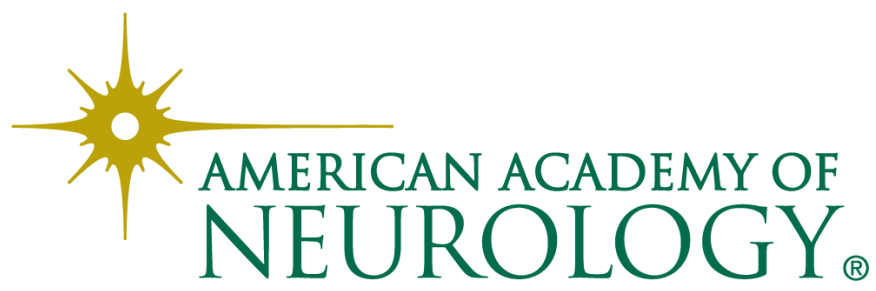

